\title{
Unit of Time
}

National Cancer Institute

\section{Source}

National Cancer Institute. Unit of Time. NCI Thesaurus. Code C42574.

An indication of the type of unit of measure being used to express a time. 